\title{
Comparative analysis of chloroplast genomes for five Dicliptera species (Acanthaceae): molecular structure, phylogenetic relationships, and adaptive evolution
}

\author{
Sunan Huang ${ }^{1,2}$, Xue-jun Ge ${ }^{1}$, Asuncion Cano ${ }^{3}$, Betty M Salazar $^{3}$, Yunfei Deng ${ }^{\text {Corresp. }{ }^{1}}$ \\ ${ }^{1}$ Key Laboratory of Plant Resources Conservation \& Sustainable Utilization, South China Botanical Garden, Chinese Academy of Sciences, Guangzhou, \\ Guangdong, China \\ 2 University of Chinese Academy of Sciences, Beijing, China \\ 3 Facultad de Ciencias Biológicas y Museo de Historia Natural, Universidad Nacional Mayor de San Marcos, Lima, Peru \\ Corresponding Author: Yunfei Deng \\ Email address: yfdeng@scbg.ac.cn
}

The genus Dicliptera (Justicieae, Acanthaceae) consists of approximately 150 species distributed throughout the tropical and subtropical regions of the world. Newly obtained chloroplast genomes (cp genomes) are reported for five species of Dilciptera ( $D$. acuminata, $D$. peruviana, $D$. montana, $D$. ruiziana and $D$. mucronata) in this study. These cp genomes have circular structures of 150689-150811 bp and exhibit quadripartite organizations made up of a large single copy region (LSC, 82796-82919 bp), a small single copy region (SSC, 17084-17092 bp), and a pair of inverted repeat regions (IRs, 25401-25408 bp). Guanine-Cytosine (GC) content makes up 37.9\%-38.0\% of the total content. The complete $\mathrm{cp}$ genomes contain 114 unique genes, including 80 protein-coding genes, 30 transfer RNA (tRNA) genes, and 4 ribosomal RNA (rRNA) genes. Comparative analyses of nucleotide variability $(\mathrm{Pi})$ reveal the 5 most variable regions (trnY-GUA-trnEUUC, trnG-GCC, psbZ-trnG-GCC, petN-psbM, and rps4-trnL-UUA), which may be used as molecular markers in future taxonomic identification and phylogenetic analyses of Dicliptera. A total of 55-58 simple sequence repeats (SSRs) and 229 long repeats were identified in the cp genomes of the five Dicliptera species. Phylogenetic analysis identified a close relationship between $D$. ruiziana and $D$. montana, followed by $D$. acuminata, $D$. peruviana, and $D$. mucronata. Evolutionary analysis of orthologous protein-coding genes within the family Acanthaceae revealed only one gene, ycf15, to be under positive selection, which may contribute to future studies of its adaptive evolution. The completed genomes are useful for future research on species identification, phylogenetic relationships, and the adaptive evolution of the Dicliptera species. 


\section{Comparative analysis of chloroplast genomes for five Dicliptera species (Acanthaceae): molecular structure, phylogenetic relationships, and adaptive evolution}

1 Sunan Huang ${ }^{1,2}$, Xue-jun Ge ${ }^{1}$, Asuncion Cano ${ }^{3}$, Betty Millan Salazar ${ }^{3}$, and Yunfei Deng 21 ,*

$3 \quad{ }^{1}$ Key Laboratory of Plant Resources Conservation \& Sustainable Utilization, South China

4 Botanical Garden, Chinese Academy of Sciences, Guangzhou, 510650, China

$5 \quad 2$ University of Chinese Academy of Sciences, Beijing, 100049, China

$6 \quad{ }^{3}$ Facultad de Ciencias Biológicas y Museo de Historia Natural, Universidad Nacional Mayor de

7 San Marcos, A venida Germán Amezaga 375, Lima 1, Perú

8 Corresponding Author:

9 Yunfei Deng ${ }^{1}$

10 No.723, Xingke Road, Tianhe District, Guangzhou, 510650, China

11 Email address: yfdeng@,scbg.ac.cn

12 


\section{Abstract}

The genus Dicliptera (Justicieae, Acanthaceae) consists of approximately 150 species distributed throughout the tropical and subtropical regions of the world. Newly obtained chloroplast genomes (cp genomes) are reported for five species of Dilciptera (D. acuminata, D. peruviana, D. montana, D. ruiziana and D. mucronata) in this study. These cp genomes have circular structures of 150689-150811 bp and exhibit quadripartite organizations made up of a large single copy region (LSC, 82796-82919 bp), a small single copy region (SSC, 17084-17092 bp), and a pair of inverted repeat regions (IRs, 25401-25408 bp). Guanine-Cytosine (GC) content makes up $37.9 \%-38.0 \%$ of the total content. The complete cp genomes contain 114 unique genes, including 80 protein-coding genes, 30 transfer RNA (tRNA) genes, and 4 ribosomal RNA (rRNA) genes. Comparative analyses of nucleotide variability (Pi) reveal the 5 most variable regions ( $\operatorname{trn} Y$ GUA-trnE-UUC, trnG-GCC, $p s b Z$-trnG-GCC, pet N-psbM, and rps4-trnL-UUA), which may be used as molecular markers in future taxonomic identification and phylogenetic analyses of Dicliptera. A total of 55-58 simple sequence repeats (SSRs) and 229 long repeats were identified in the cp genomes of the five Dicliptera species. Phylogenetic analysis identified a close relationship between D. ruiziana and D. montana, followed by D. acuminata, D. peruviana, and D. mucronata. Evolutionary analysis of orthologous protein-coding genes within the family Acanthaceae revealed only one gene, $y c f 15$, to be under positive selection, which may contribute to future studies of its adaptive evolution. The completed genomes are useful for future research on species identification, phylogenetic relationships, and the adaptive evolution of the Dicliptera species.

\section{Introduction}

The genus Dicliptera Juss. belongs to tribe Justicieae of the family Acanthaceae; it consists of approximately 150 species, which are typically found in the tropical and subtropical regions of the world (Scotland \& Vollesen, 2000; Mabberley, 2017). It is readily recognized by umbellately arranged, rarely solitary, cymose inflorescence units (cymules) subtended by conspicuously paired bracts, anthers with two partially or completely superposed thecae and, in the Palaeotropics, resupinate corollas that lack a rugula (Darbyshire, 2008). Eleven species of Dicliptera are found in Peru, most of which are located in the Andes (Brako \& Zarucchi, 1993; León, 2006). Species such as Dicliptera chinensis, D. peruviana, and D. verticillata are used in traditional herbal medicines in China and Peru (Bussmann \& Glenn, 2010; Horacio et al., 2007; Telefo et al., 2002; Zhang et al., 2010). Species delimitation within Dicliptera is difficult (Balkwill et al., 1996) due, in part, to the remarkable uniformity of the floral morphology in the majority of the taxa. Its taxonomy is also confounded by the presence of several widespread species complexes (Darbyshire, 2008). The taxonomic difficulties make it important to analyze the species using molecular analysis, infrageneric classification, and the relationships within Dicliptera. Kiel et al. (2017) conducted the only phylogenetic analysis of the tribe Justicieae, 
50

51

52

53

54

55

56

57

58

59

60

61

62

63

64

65

66

67

68

69

70

71

72

73

74

75

76

77

78

79

80

81

82

83

84

85

86

using five chloroplast regions ( $n d h F-\operatorname{trn} L, \operatorname{trn} T$-trnL-UAG, trnS-trnG, ndhA, rpl16) and one nuclear region (nrITS). However, the interspecific relationships within Dicliptera have not been determined because of the limited number of samples available.

Five common Peruvian species were collected, representing the genus Dicliptera (D. acuminata, D. peruviana, D. montana, D. mucronata, and D. ruiziana). D. acuminata, D. montana, and D. peruviana are used in the agroindustrial industry (Victor et al., 2017); D. peruviana is a traditional herbal medicine used by the Andeans of Canta, Lima, Peru to alleviate stomach aches (Horacio et al., 2007); D. mucronata is distributed mainly in Central America and is easily confused with D. scabra (Victor et al., 2017); D. ruiziana is found throughout Peru to elevations of about $3000 \mathrm{~m}$ (Antonio et al., 2009). All five species were collected in Southeast Peru and were distinguished from each other by the character of their leaves, bracts, bracteoles, and calyxes (Table 1). However, species delimitation is difficult without the aid of the flowers and the distribution of the five Dicliptera species is often overlapping. Species determinations in Central America are predominantly made by morphological comparisons as opposed to molecular comparisons. The study of the complete cp genomes of five Dicliptera species may encourage more effective species identification within the genus Dicliptera, especially in Central America.

The chloroplast genome (cp genome) is an independent genome that has been used in many evolutionary studies (Fan et al., 2018; Gao et al., 2018; George et al., 2015; Chen et al., 2018; Inkyu et al., 2018; Kim et al., 2004; Lin et al., 2016; Mader et al., 2018; Meng et al., 2018; Ma et al., 2017; Raubeson et al., 2007; Wang et al., 2008; Wu et al., 2018). It has a simple structure with a low molecular weight and multiple copies. Most of the $\mathrm{cp}$ genomes have circular structures with quadripartite organizations composed of one large single copy region (LSC), one small single copy region (SSC), and a pair of inverted regions (IRs). However, there are numerous exceptions to the common structure, like the IR-lacking clade (IRLC) in Fabaceae (Fan et al., 2018; Gao et al., 2018; George et al., 2015; Chen et al., 2018; Inkyu et al., 2018; Kim et al., 2004; Lin et al., 2016; Mader et al., 2018; Meng et al., 2018; Erika et al., 2015). The complete cp genomes of more than 2400 plants have been published, to date, in the NCBI database (http://www.ncbi.nlm.nih.gov/genome). The majority of plant cp genomes are 110 to $170 \mathrm{~kb}$ in length (Olmstead \& Palmer, 1994; Weng et al., 2013; Wicke et al., 2011). The family Acanthaceae is a large family with approximately 230 genera and 4300 species, yet only ten species from this family have fully sequenced cp genomes (Table S1).

The complete chloroplast genome is widely used for species identification, phylogenic studies, and studies in adaptive evolution (Lin et al., 2016; Ma et al., 2017; Fan et al., 2018; Gao et al., 2018). Adaptive evolution is defined as the suitability for the improvement of a species during its evolutionary processes. It is always driven by evolutionary processes such as natural selection and leads to biological pressures and biodiversity at all levels of biological organization (Yang \&

Peer) reviewing PDF | (2019:06:38740:2:0:NEW 16 Dec 2019) 
87 Swanson, 2002; Scott Phillips et al., 2014; Hall et al., 2008). The non-synonymous

$88\left(\mathrm{~K}_{\mathrm{A}}\right) /$ synonymous rate $\left(\mathrm{K}_{\mathrm{S}}\right)$ ratio $\left(\omega=\mathrm{K}_{\mathrm{A}} / \mathrm{K}_{\mathrm{S}}\right)$ provides a measure of selective pressure at the

89 amino acid level. As suggested by Makalowski and Boguski (1998), the $\omega$ values less than one

$90\left(\mathrm{~K}_{\mathrm{A}} / \mathrm{K}_{\mathrm{S}}<1\right)$ indicate that the gene is under negative selection and vice versa (Wojciech et al.,

91 1998; Meng et al., 2018). Recent studies have detected many positively selected chloroplast 92 genes $\left(\mathrm{K}_{\mathrm{A}} / \mathrm{K}_{\mathrm{S}}>1\right)$, such as the $n d h C, n d h J, p s b K, p s b N$, rpl14, rpl16, rps 4, rps 15, rps 18, rps 19,

93 infA, and $r p o B$ genes in Echinacanthus and the petA, psbD, psbE, ycf3, psaI, rps 4, psbM, ndhE,

$94 n d h G$ and rpoCl genes in Allium (Gao et al., 2018; Xie et al., 2019).

95 The cp genomes of five Dicliptera species were sequenced, compared, and reported for the first time in this study. The five most variable regions were identified through genome comparison analysis and nucleotide variability; these were chosen as candidate molecular markers for taxonomic identification and systematic analysis in the future. Codon usage analysis was conducted to find the codon bias in the genus Dicliptera. 285 simple sequence repeats (SSRs), 21 polymorphic SSRs, and 229 long repeats were detected and described. The phylogenetic relationships of the five species and other members of the family Acanthaceae were analyzed. Finally, the orthologous protein-coding genes were identified in the family Acanthaceae and the selective pressure for these genes was analyzed. This work may contribute to future adaptive evolution analysis of the Acanthaceae species.

Materials and methods

Plant materials and DNA extraction

107 Fresh leaf tissues were collected during several botanical surveys conducted by South China

108 Botanical Gardens, Chinese Academy of Sciences and Facultad de Ciencias Biológicas y Museo

109 de Historia Natural, Universidad Nacional Mayor de San Marcos in Peru. The samples were

110 dried in silica gel immediately after collection. Voucher specimens were deposited at the Museo

111 de Historia Natural, Universidad Nacional Mayor de San Marcos (USM) and the herbarium of

112 South China Botanical Garden, Chinese Academy of Sciences (IBSC) (Table 2). The specimens

113 were visually identified by Deng Yunfei and the total genomic DNA was extracted using a

114 modified CTAB method (Doyle \& Doyle, 1987) that included 4\% CTAB with 2\% polyvinyl

115 polypyrrolidone (PVP) (Yang et al., 2014a).

\section{Genome sequencing, assembly, and annotation}

117 Short-insert (300-500 bp) libraries were constructed using the Nextera XT DNA Library Prep Kit 118 (Illumina) following the manufacturer's instructions. Illumina $\mathrm{x}$ Ten instruments at BGI-Wuhan 119 were used to perform paired-end (PE) sequencing for each sample. GetOrganelle v. 1.6.2 (Jin et 120 al., 2018) was used to assemble the sequenced PE reads. Andrographis paniculata (GenBank accession no. NC_022451) served as a reference and the sequenced reads were filtered using Bowtie2 v. 2.3.5.1 (Langmead \& Salzberg, 2012); SPAdes v. 3.13.1 (Bankevich et al., 2012) was used to assemble the filtered plastid reads and the final "fastg" files were reduced using the "slim_fastg.py" script in GetOrganelle to retain the pure plastid contigs; the filtered De Brujin 
125 graph files were transferred to Bandage v. 0.8.1 (Wick et al., 2015) for visualization and to 126 obtain the paths of the final "fasta" files of the cp genomes; finally, the genome structures of all 127 five species were compared to the reference genome using Mauve v. 1.1.1 software (Darling et

128 al., 2010) to determine the accuracy of the final genome. The assembled cp genome was

129 annotated using PGA v. 2019 (Qu et al., 2019) using the annotated $A$. paniculata as a reference.

130 The boundaries of the annotated genes were manually modified and coupled with CDSs in

131 Geneious v. 2019.0.3 (Kearse et al., 2012). All transfer RNA (tRNA) genes were determined

132 using tRNAscan-SE v. 2.0 (Schattner et al., 2005). The annotated cp genome files were

133 submitted to OGDRAW v. 1.3.1 (https://chlorobox.mpimp-golm.mpg.de/OGDraw.html)

134 (Greiner et al., 2019) to create a circular cp genome map for each species. The five cp genomes

135 (D. acuminata, MK830556; D. pruviana, MK833945; D. montana, MK833946; D. ruiziana,

136 MK833947; D. mucronata, MK848596) were submitted to Genbank.

\section{Genome comparison and structural analysis}

138 Five cp genomes were compared using mVISTA v. 2.0 (Frazer et al., 2004) with Shuffle-

139 LAGAN mode and the annotation of D. acuminata as a reference (Brudno et al., 2003). The

140 conserved regions were visualized on an mVISTA plot. DnaSP v. 5.1 (Librado \& Rozas, 2009)

141 was used to calculate the nucleotide variance (Pi) within the five Dicliptera species. The SC and

142 IR boundaries were compared with $A$. paniculata as a reference. The Relative Synonymous

143 Codon Usage (RSCU) of all protein-coding genes was analyzed for each species using CondoW

144 v. 1.4.2 (Sharp \& Li, 1987). MISA v. 1.0 (Thiel et al., 2003) was used to identify the simple

145 sequence repeats (SSRs). The locations and lengths of long repeats (including forward,

146 palindrome, complement, and reverse repeats) were analyzed using REPuter v. 2.74 (Kurtz et al.,

147 2001) with the minimum repeat size set to $20 \mathrm{bp}$. Tandem repeats were identified using Tandem

148 Repeats Finder v. 4.09 (Benson, 1999).

\section{Phylogenetic analyses}

150 Phylogenetic analysis was conducted for all of the sequenced cp genomes (each cp genome

151 included only one IR), including the five species reported in this study and ten previously

152 reported species of Acanthaceae (Table S1). Sesamum indicum (NC_016433) (Pedaliaceae) and

153 Mentha spicata (NC_037247) (Lamiaceae) were used as outgroups. The complete cp genomes

154 were aligned using MAFFT v. 1.3.7 (Katoh \& Standley, 2013) and were adjusted manually as

155 needed. The substitution models with the best fit were chosen by MrModeltest v. 2.3 (Nylander,

156 2004) based on the Akaike Information Criterion (AIC). RAxML v. 8.0.0 (Stamatakis, 2014) was

157 used to reconstruct the phylogenetic relationship with the maximum likelihood (ML) method.

158 Maximum parsimony (MP) analysis was run in Paup v. 4.0a (Swofford, 2003). Bootstrap values

159 exceeding $50 \%$ were shown next to the corresponding branches. Bayesian inference (BI) analysis

160 was conducted using MrBayes 3.2.7 (Ronquist \& Huelsenbeck, 2003) with posterior

161 probabilities (PP) obtained for each branch.

\section{Selective pressure analysis}

163 OrthoMCL v. 2.0 (Li et al., 2003) was used to find the orthologous genes for the family

164 Acanthaceae. The sequences for each orthologous gene were aligned separately using MAFFT v.

165 1.3.7 (Katoh \& Standley, 2013). The nonsynonymous $\left(\mathrm{K}_{\mathrm{A}}\right)$ and synonymous $\left(\mathrm{K}_{\mathrm{S}}\right)$ substitution

Peer] reviewing PDF | (2019:06:38740:2:0:NEW 16 Dec 2019) 
166 rates were calculated using PAML v. 4.9 with the codeml program to analyze the selective

167 pressures of every orthologous gene sequence (Yang, 2007). The $\omega$ value $\left(\omega=K_{A} / K_{S}\right)$ was

168 estimated using the method reported by Yang and Nielsen (2000). The genes under positive

169 selection were confirmed by computing the likelihood ratio tests (LRTs).

\section{Results}

\section{Chloroplast genome features}

172 The average assemblies of the five cp genomes varied from 1918.3 to $3727.5 \mathrm{bp}$. The cp genome

173 sequences were 150738 bp (Dicliptera acuminata), 150811 bp (D. peruviana), 150689 bp (D.

174 montana), 150750 bp (D. ruiziana), and 150720 bp (D. mucronata) in length (Table 2). Each of

175 the sequences encoded 80 protein-coding genes, 30 transfer RNA (tRNA) genes, and 4 ribosomal

176 RNA (rRNA) genes (Table 2 and S2; Figure 1), of which three protein-coding genes had two

177 introns and nine had one intron. The Rps 12 gene was trans-spliced because of the locations of the

178 first exon at the LSC and the other two exons at the IRs. Six protein-coding genes ( $r p l 2, r p l 23$,

$179 y c f 2, y c f 15, n d h B$, and $r p s 7$ ), seven tRNA (trnI-CAU, trnI-GAU, trnL-CAA, trnN-GUU, trnR-

180 ACG, $\operatorname{trn} V$-GAC, and $\operatorname{trn} A$-UGC), and all four rRNA ( $r r n 4.5, r r n 5, r r n 16$ and $r r n 23)$ had two

181 copies because of their location at the IR regions. The rps 12 gene was identified as the

182 pseudogene in D. mucronata by the existence of internal stop codons.

183 The five cp genomes displayed a typical quadripartite structure, including a large single copy

184 (LSC) region (range from 82796-82919 bp), a small single copy (SSC) region (range from

185 17084-17092 bp), and a pair of inverted repeat (IR) regions (25401-25408 bp; Table 2). The

186 Guanine-Cytosine (GC) content of the cp genomes of the five Dicliptera was approximately

$18738.0 \%$. The GC content in the IR regions (43.3-43.4\%) was noticeably above that of the LSC

188 (36.0\%) and SSC (31.6-31.9\%) regions in each cp genome.

\section{IR contraction and expansion}

190

The IR/LSC and IR/SSC borders of the cp genomes of the five Dicliptera species and the $A$. paniculata were compared to identify the expansion or contraction of the $I R$ (Figure 2 ). The genes, rps 19, rpl2, $n d h F, y c f 1$, and $p s b A$ were present at the juncture of the LSC/IRa, IRa/SSC, $\mathrm{SSC} / \mathrm{IRb}$, and IRb/LSC borders. The five Dicliptera species have identical IR/SC borders with the exception of the $y c f 1$ gene at the SSC/IRb border in D. montana, which varies from those in A. paniculata. There are $167 \mathrm{bp}$ from the border of rpl2 to the juncture of LSC/IRa of Dicliptera, while this distance is just $57 \mathrm{bp}$ in A. paniculata. The rps 19 gene is on the LSC/IRa border in all five Dicliptera species, indicating that this border has moved toward the LSC region when compared to A. paniculata. The $n d h F$ gene in Dicliptera is situated at the junction of the $\mathrm{IRa} / \mathrm{SSC}$ region and has $117 \mathrm{bp}$ sequences located at IRa, however, the comparable region in $A$. paniculata is $40 \mathrm{bp}$ long, indicating that the IRa/SSC boundary has moved toward the SSC region. The $y c f l$ gene is located at the $\mathrm{IRb} / \mathrm{SSC}$ junction and the border has moved toward the 
203

204

205

206

207

208

209

210

211

212

213

214

215

216

217

218

219

220

221

222

223

224

225

226

227

228

229

230

231

232

233

234

235

236

237

238

A. paniculata, respectively. The $y c f 1$ gene duplications located in IRa are $811-812 \mathrm{bp}$ in Dicliptera and 982 bp in A. paniculata, indicating a slight expansion of the IR regions. Likewise, the space in Dicliptera from $p s b A$ to the IRb/LSC boundary (364 bp) is enlarged compared to that of $A$. paniculata (333 bp). These findings reveal that the IR regions in the cp genome of Dicliptera have expanded compared to those of $A$. paniculata.

\section{Comparative chloroplast genome analysis}

The annotated $D$. acuminata cp genome was used as a reference in mVISTA for the alignment of the cp genome among the five Dicliptera species (Figure 3). The size and gene order of the chloroplast genomes of the Dicliptera species are conserved, but some divergent regions were identified, including the trnH-GUG, $r p l 16$, pet N-psbM, trnS-trnG, trnT-trnF, ndhC-trnV, petA$p s b J$, and $r p s 12-c l p P$ genes. The nucleotide variability $(\mathrm{Pi})$ was calculated for the coding and non-coding regions, respectively, in order to further confirm the sequence variations (Table S3, Figure 4). However, the Pi values are rather low among the five species (0 to 0.02230$)$ and a total of 5 hotspot regions were identified with $\mathrm{Pi}>0.005$ ( $\operatorname{trn} Y$-GUA-trnE-UUC, $\operatorname{trn} G$-GCC, psbZ-trnG-GCC, pet N-psbM, and rps4-trnL-UUA).

\section{Codon usage}

A total of 78714-78747 bp protein-coding genes were identified in the five Dicliptera $\mathrm{cp}$ genomes, accounting for $52.19 \%-52.24 \%$ of the entire genome sequence. These genes are encoded in 26238-26249 codons. Leucine (Leu, encoded by UUA, UUG, CUU, CUC, CUA and CUG) was the most frequent amino acid encoded by these codons, comprising 2825-2828 $(10.8 \%)$ of the total number of codons; cysteine (Cys, encoded by UGU and UGC) was the least frequently encoded amino acid, with 303-305 codons (1.2\%) (Figure 5). For all codons, from the first to third position, the AU contents are 55.8\%-60.2\%, 60.6\%-64.1\%, and 64.9\%-65.8\%, respectively. The majority of the preferred codons (RSCU>1) ended with A or U, with the exception of UUG (RSCU=1.25). This phenomenon is congruent with the results from other plant studies (Table S4) (Lu et al., 2018; Yang et al., 2014b; Yi \& Kim, 2012).

\section{Simple Sequence Repeats (SSRs) and long repeat analysis}

A total of 285 SSRs were identified in this study. The numbers of mono-, di-, tri-, and tetranucleotides were 157, 37, 55, and 36, respectively (Tables S5 and S7). Mononucleotide repeats were the most common repeats, accounting for $55.1 \%$ of the total repeats, while dinucleotides repeats accounted for $13.0 \%$, and other SSRs occurred less frequently (Figure 6A). The SSR varied in number and type depending on the species; $D$. acuminata and D. montana (58) had the most SSRs and D. mucronata (55) had the least (Figure 6B, Table 3). Five categories of long repeats (tandem, complement, forward, palindromic and reverse repeats) were detected and analyzed in the five Dicliptera cp genomes (Table S6 and S7, Figure 6C). 229 long repeats were identified and were composed of 128 tandem repeats, 8 complement repeats, 53 
239 forward repeats, 38 palindromic repeats, and 2 reverse repeats (Figure 6C). The number of

240 repeats was highest in D. peruviana (56) and lowest in D. montana (41) (Figure 6D).

\section{Phylogenetic analyses}

242 GTR and SYM+G were the best fit models used for the ML and BI trees to display the

243 completed cp genomes. The data matrix for all of the MP, ML, and BI analyses revealed trees

244 with highly congruent topologies. The phylogenetic relationships within the $17 \mathrm{cp}$ genomes

245 sequences analyzed were well-resolved (Figure 7). Our phylogenetic analyses strongly support

246 the monophyly of the Dicliptera species $\left[\mathrm{BP}(\mathrm{MP})=100 \%, \mathrm{BP}_{(\mathrm{ML})}=100 \%, \mathrm{PP}=1.0\right]$, in which $D$.

247 ruiziana has the closest relationship with $D$. montana $\left[\mathrm{BP}_{(\mathrm{ML})}=52 \%, \mathrm{PP}=0.96\right]$, followed by $D$.

248 acuminata $\left[\mathrm{BP}_{(\mathrm{ML})}=69 \%, \mathrm{PP}=0.97\right]$, D. peruviana $\left[\mathrm{BP}(\mathrm{MP})=99.8 \%, \mathrm{BP}_{(\mathrm{ML})}=100 \%, \mathrm{PP}=1.0\right]$, and

249 D. mucronata $\left(\mathrm{BP}_{[\mathrm{MP}]}=100 \%, \mathrm{BP}_{[\mathrm{ML}]}=100 \%, \mathrm{PP}=1.0\right)$.

\section{Selective pressure events}

251 There were 68 orthologous protein-coding genes found in this study. The $\omega$ values of most genes

252 were low $(\omega<1)$, approaching zero, except for the $y c f 15$ gene found in the SSC region, which

253 had a ratio of 1.4453 . The $\omega$ value of the $\operatorname{mat} K$ gene was 0.9418 , indicating a relaxed selection

254 (Table S8, Figure 8).

\section{Discussion}

\section{Sequence variation among five Dicliptera species}

257 The results of our study showed that the cp genomes of five Peruvian Dicliptera species were similar in structure, content, and order (Table 2, Figure 1). The cp genomes ranged in size from 150689 bp to 150811 bp in D. montana and D. peruviana, respectively. These structures are longer than the cp genome of A. paniculata (15249 bp) (Ding et al., 2016). The genome size of all Dicilptera is relevant to LSC variation (Table 2) and this phenomenon has also been identified in other species (Zhao et al., 2018; Li et al., 2018; Meng et al., 2018). mVISTA revealed a low divergence between the genomes of the five Dicliptera species, suggesting that the cp genomes were conserved. The IR regions were more highly conserved than the SC regions and the coding regions were less variable than the non-coding regions, which is also found in other angiosperms (Gao et al., 2018; Meng et al., 2018; Li et al., 2018; Yan et al., 2019). regions may be a result of copy corrections during gene conversion, which can correct or delete the mutation. Codons were shown to have a strong tendency toward $\mathrm{A}$ or $\mathrm{U}$ at the third codon position, which is similar to the expression of an A/U ending in other plants (Gao et al., 2017; Clegg et al., 1994; Mader et al., 2018; Meng et al., 2018). This phenomenon may explain why

272 the Adenine-Thymine (AT) content is slightly higher than the GC content in the cp genome of

273 Dicliptera. 


\section{IR expansion analysis}

275 IR regions are the most conserved regions in the cp genomes. Frequent expansions and

276

277

278

279

280

281

282

283

284

285

286

287

288

289

290

291

292

293

294

295

296

297

298

299

300

301

302

303

304

305

306

307

308

309

310

311

312

313

314

contractions at the junctions of SSR and LSC with IRs illustrate the relationships among taxa and have been recognized as evolutionary signals (Khakhlova et al., 2006; Inkyu et al., 2018; Lu et al., 2018; Raubeson et al., 2007; Wang et al., 2008). In this study, only a few variations were found among the five Dicliptera species. When compared with the cp genome of $A$. paniculata, the IR regions of the cp genome of Dicliptera revealed a slight expansion. The size differences among the cp genome of the five Dicliptera species (150689-150811 bp) and Andrographis paniculata (150249 bp) are congruent with the results of previous studies. The contractions and expansions at the LSC/IRs and SSC/IRs junctions contribute to the size variations of the cp genomes (Kim \& Lee, 2004; Raubeson et al., 2007). Gene conversion during speciation is thought to be responsible for small IR expansions or contractions. (Wang et al., 2008; Goulding et al., 1996; Olga et al., 2006; Meng et al., 2018; Choi et al., 2019).

\section{Molecular markers}

Simple sequence repeats (SSRs), known as microsatellites, are short stretches of DNA which consist of only one, or a few, tandemly repeated nucleotides. Polymorphic SSRs are the same units with different unit numbers located in the homologous regions; these are frequently used to identify variable species complexes (Diethard et al., 1984; Jerzy et al., 1995; George et al., 2015; Gao et al., 2018). 21 SSRs were identified as polymorphic SSRs among the five Dicliptera species; these may be used as candidate genetic markers for further phylogenetic studies in the genus Dicliptera (Table 3). The presence of these repeats indicates that these regions are important hotspots for genome recombination. All polymorphic SSRs are located in LSC/SSC regions. Polymorphic SSRs are mainly distributed in non-coding regions, which are also highly variable regions in the chloroplast genomes (Asaf et al., 2017). The presence of long sequence repeats are indicators of mutational hotspots (Borsch \& Quandt, 2009; Jiang et al., 2018).

The $y c f 1$ gene was previously reported for its use in DNA barcodes due to its abundance of variable sites (Kurt et al., 2008; David et al., 2009; Dong et al., 2012; Drew et al., 2013; Dong et al., 2015). Shingo et al. (2013) concluded that the ycfl gene is crucial for plant viability because it encodes the Arabidopsis protein, Tic214, which is essential for photosynthetic protein import. A substantial size difference was noted between the $y c f 1$ gene of the five Dilicptera species (5354-5355 bp) and A. paniculata (5542 bp). The nucleotide variability of the $y c f 1$ gene $(\mathrm{Pi}=0.0109)$ was slightly higher than that of the regions matK $(\mathrm{Pi}=0.00107)$ and $r p l 16$ $(\mathrm{Pi}=0.00103)$. The two regions are currently used in the DNA barcodes for the tribe Justicieae and other angiosperms (Kiel et al., 2017; Särkinen \& George, 2013). Therefore, the $y c f 1$ gene should be a potential molecular marker for the Diciptera species as well. The most divergent regions among the Dicliptera species, as determined by a comparison of nucleotide variability, are $r p s 4$-trnL-UUA $(\mathrm{Pi}=0.02230)$, pet $N$-psbM $(\mathrm{Pi}=0.00783)$, psbZ-trnG-GCC ( $\mathrm{Pi}=0.00697)$, $\operatorname{trn} G$-GCC $(\mathrm{Pi}=0.00571)$, and $\operatorname{trn} Y$-GUA-trnE-UUC $(\mathrm{Pi}=0.00526)$. The variability in these regions was much higher than that in the coding regions and the highly variable regions identified here could be validated and used as molecular markers in future species delimitation and phylogenetic studies.

Peer) reviewing PDF | (2019:06:38740:2:0:NEW 16 Dec 2019) 


\section{Phylogenetic Analyses}

316 The phylogenetic trees (MP, ML and BI) demonstrated a significant relationship among

317 Acanthaceae with high bootstrap values and posterior probabilities (Figure 7). The genus

318 Aphelandra was found to be the earliest diverging lineage; tribes Justicieae and Ruellieae are

319 strongly supported as monophyletic groups $\left[\mathrm{BP}_{(\mathrm{MP})}=100 \%, \mathrm{BP}_{(\mathrm{ML})}=100 \%, \mathrm{PP}=1.0\right]$ that form

320 sister groups with each other. The results are consistent with previous studies (Mcdade et al.,

321 2008; Huang et al., 2019). Phylogenetic analysis strongly supports Dicliptera as a monophyletic

322 group. The clade formed by all five Dicliptera species is a sister to the species Justicia

323 leptostachya $\left[\mathrm{BP}_{(\mathrm{MP})}=100 \%, \mathrm{BP}_{(\mathrm{ML})}=100 \%, \mathrm{PP}=1.0\right]$, which supports the conclusion by Kiel et

324 al. (2017) that the genus Dicliptera should be placed in the justicioid lineage. D. mucronata and

325 D. peruviana are the first and second diverging clades among the five Dicliptera species; $D$.

326 acuminata, D. ruiziana, and D. montana are species that can confidently be assigned to one

327 clade. Trees with the same topology were retrieved from the ML and BI analyses. D. ruiziana

328 was most closely related to D. montana, followed by D. acuminata. However, the relationships

329 among $D$. acuminata, D. ruiziana and D. montana were not resolved using MP analysis. The

330 sister relationship between $D$. ruiziana and D. montana is supported by their shared

331 morphological characteristics, including a lanceolate calyx and ovate leaves of 1.0-1.5 $\times 0.8-1.0$

$332 \mathrm{~cm}$ versus the has subulate calyx and oblong-lanceolate leaves of 3.5-7.0 $\times 1.5-2.5 \mathrm{~cm}$ of $D$.

333 acuminata (Table 1).

\section{Adaptive evolution analysis}

335 Positively selected genes are known to play a key role in adapting to different environments (Lin 336 et al., 2016; Ma et al., 2017; Fan et al., 2018; Gao et al., 2018; Wu et al., 2018) and it is

337 important to understand the adaptive evolutionary history of Acanthaceae. Orthologous genes

338 are a particular class of homologous genes that diverged following the speciation of their host

339 species; they are ideal markers for analyzing evolutionary history (Gargaud et al., 2015). 68

340 protein-coding genes were found to be orthologous in the family Acanthaceae and the selective

341 pressure of these genes was measured. The resulting measurements found that most genes in the

342 family Acanthaceae were under negative selection $(\omega<1)$ except for $y c f 15(\omega=1.4453)$.

343 According to previous studies, the $y c f 15$ gene is a member of the PFAM protein family accession

344 PF10705 (Sara et al., 2019) and was not considered to be a protein-coding gene because of its

345 unknown function (Steane, 2005; Feng et al., 2018). The ycf15 gene acts as a pseudogene in

346 some species because of its premature stop codons (Chen et al., 2018; Jiang et al., 2018). The

$347 y c f 15$ gene should be further investigated for its role in adaptive evolution and gene function.

\section{Conclusions}

349 Our study sequenced and analyzed the complete cp genomes of five Peruvian Dicliptera species

350 (D. acuminata, D. peruviana, D. montana, D. ruiziana, and D. mucronata) for the first time. The 
351 identification of the chloroplast genomes and the new molecular markers of these five species

352 contributes to the genetic resources available for future identification and phylogenetic studies.

353 The goal of this study was to determine the appropriate DNA barcode for the identification of the

354 Diciptera species, especially those found in Peru. The genes ycf1, rps4-trnL-UUA, petN-psbM,

355 psbZ-trnG-GCC, trnG-GCC, and trnY-GUA-trnE-UUC were found to be the most suitable DNA

356 barcode for the species Dicliptera. The interspecies relationships among the five species were

357 resolved. However, further phylogenetic analysis using additional genes from the nucleus will

358 have to be conducted in order to understand how gene introgression and hybridization affects the

359 phylogeny of Dicliptera (Birky, 1995; Meng et al., 2018; Lu et al., 2018). A single gene, ycf15,

360 was found to be positively selected among all of the protein coding genes that were identified.

361 This gene may play an important role in the adaptive evolution of the Acanthaceae species and

362 its function should to be further studied. Our genome data enhances the cp genome resources for

363 the family Acanthaceae and our understanding of its species identification, phylogeny, and

364 evolutionary history.

365 References

366

367

368

369

370

371

372

373

374

375

376

377

378

379

380

381

382

383

384

385

386

387

Antonio Galán de Mera, Eliana Linares Perea, José Campos de la Cruz and José Alfredo Vicente Orellana. 2009. Nuevas observaciones sobre la vegetación del sur del Perú. Del Desierto Pacífico al Altiplano. Acta Botanica Malacitana 34:107-144.

Balkwill K, Norris FG, and Balkwill M-J. 1996. Systematic studies in the Acanthaceae; Dicliptera in southern Africa. Kew Bulletin 51:1-61.

Bankevich A, Nurk S, Antipov D, Gurevich AA, Dvorkin M, Kulikov AS, Lesin VM, Nikolenko SI, Pham S, and Prjibelski AD. 2012. SPAdes: a new genome assembly algorithm and its applications to single-cell sequencing. Journal of computational biology 19:455-477.

Benson G. 1999. Tandem repeats finder: a program to analyze DNA sequences. Nucleic acids research 27:573-580.

Birky CW. 1995. Uniparental inheritance of mitochondrial and chloroplast genes: mechanisms and evolution. Proceedings of the National Academy of Sciences 92:11331-11338.

Borsch T. and Quandt D. 2009. Mutational dynamics and phylogenetic utility of noncoding chloroplast DNA. Plant Systematics and Evolution 282:169-199.

Brako L. and Zarucchi J. 1993. Catálogo de las An`giospermas y Gimnospermas del Perú. Monograph in Systematic Botany from Missouri Botanic Gardens 45: 1-1286.

Brudno M., Malde S., Poliakov A., Do C.B., Couronne O., Dubchak I., and Batzoglou S. 2003. Glocal Alignment: Finding Rearrangements During Alignment. Bioinformatics 19S1: i54-i62.

Bryan T. Drew and Kenneth J. Sytsma. 2013. The South American radiation of Lepechinia (Lamiaceae): phylogenetics, divergence times and evolution of dioecy. Botanical Journal of the Linnean Society 171:171-190. 
388 Bussmann RW, and Glenn A. 2010. Medicinal plants used in Northern Peru for reproductive

389

390

391

392

393

394

395

396

397

398

399

400

401

402

403

404

405

406

407

408

409

410

411

412

413

414

415

416

417

418

419

420

421

422 problems and female health. Journal of Ethnobiology and Ethnomedicine 6:30.

Yan C, Du J, Gao L, Li Y and Hou X. 2019. The complete chloroplast genome sequence of watercress (Nasturtium officinale R. Br.): Genome organization, adaptive evolution and phylogenetic relationships in Cardamineae. Gene 699:24-36.

Clegg MT, Gaut BS, Learn GH, and Morton BR. 1994. Rates and patterns of chloroplast DNA evolution. Proceedings of the National Academy of Sciences 91:6795-6801.

Darbyshire I. 2008. Notes on the genus Dicliptera (Acanthaceae) in eastern Africa. Kew Bulletin 63:361-383.

Darling AE, Mau B and Perna NT. 2010. progressiveMauve: multiple genome alignment with gene gain, loss and rearrangement. PloS one 5: e11147.

David S. Gernandt, Sergio Hernández-León, Esmeralda Salgado-Hernández, and Jorge A. Pérez de la Rosa. 2009. Phylogenetic Relationships of Pinus Subsection Ponderosae Inferred from Rapidly Evolving cpDNA Regions. Systematic botany 34:481-491.

Xie DF, Yu HX, Megan Price, Xie C, Deng YQ, Chen PJ, Yu Y, Zhou SD and He XJ. 2019. Phylogeny of Chinese Allium species in section Daghestanica and adaptive evolution of Allium (Amaryllidaceae, Allioideae) species revealed by the chloroplast complete genome. Frontiers in Plant Science 10:460.

Diethard Tautz and Manfred Renz. 1984. Simple sequences are ubiquitous repetitive components of eukaryotic genomes. Nucleic Acids research 12: 4127-4138.

Ding P, Shao Y H, Li Q, Gao J L, Zhang R J and Lai X P. 2016. The chloroplast genome sequence of the medicinal plant Andrographis paniculata. Mitochondria DNA 27:23472348.

Dong W, Xu C, Li C, Sun J, Zuo Y, Shi S, Cheng T, Guo J and Zhou S. 2015. ycf1, the most promising plastid DNA barcode of land plants. Scientific Report 5:8348.

Dong W, Liu J, Yu J, Wang L and Zhou S. 2012. Highly Variable Chloroplast Markers for Evaluating Plant Phylogeny at Low Taxonomic Levels and for DNA Barcoding. Plos one 7:e35071.

Doyle JJ, and Doyle JL. 1987. A rapid DNA isolation procedure for small quantities of fresh leaf tissue. Phytochem Bull 19:11-15.

Fan W, Wu Y, Yang J, Shahzad K, and Li Z. 2018. Comparative chloroplast genomics of Dipsacales species: Insights into sequence variation, adaptive evolution, and phylogenetic relationships. Frontiers in plant science 9:689.

Frazer KA, Pachter L, Poliakov A, Rubin EM, and Dubchak I. 2004. VISTA: computational tools for comparative genomics. Nucleic acids research 32:W273-W279. 
423

424

425

426

427

428

429

430

431

432

433

434

435

436

437

438

439

440

441

442

443

444

445

446

447

448

449

450

451

452

453

454

455

456

457

Gao C, Wang J, and Deng Y. 2018. The Complete Chloroplast Genomes of Echinacanthus Species (Acanthaceae): Phylogenetic Relationships, Adaptive Evolution, and Screening of Molecular Markers. Frontiers in plant science 9:1989.

Gargaud Muriel, Irvine William, Amils Ricardo, Cleaves Henderson James, Pinti Daniele L., Quintanilla Jose Cernicharo, Rouan Daniel, Spohn Tilman, Tirard Stephane and Viso Michel, eds. 2015. Encyclopedia of Astrobiology. Berlin, Heidelberg: Springer Berlin Heidelberg, 1803-1803.

George B, Bhatt BS, Awasthi M, George B, and Singh AK. 2015. Comparative analysis of microsatellites in chloroplast genomes of lower and higher plants. Current Genetics 61:665-677.

Goulding SE, Wolfe K, Olmstead R, and Morden C. 1996. Ebb and flow of the chloroplast inverted repeat. Molecular and General Genetics MGG 252:195-206.

Greiner S, Lehwark P and Bock R. 2019. OrganellarGenomeDRAW (OGDRAW) version 1.3.1: expanded toolkit for the graphical visualization of organellar genomes. Nucleic Acids Research. 1: gkz238.

Chen H, Junjie Shao J, Zhang H, Jiang M, Huang L, Zhang Z, Yang D, He M, Mostafa R, Luo X, Botao S, Wu W and Liu C. 2018. Sequencing and Analysis of Strobilanthes cusia (Nees) Kuntze Chloroplast Genome Revealed the Rare Simultaneous Contraction and Expansion of the Inverted Repeat Region in Angiosperm. Frontiers in plant science 9:324.

Horacio De-la-Cruz, Graciela Vilcapoma and Percy A. Zevallos. 2007. Ethnobotanical study of medicinal plants used by the Andean people of Canta, Lima, Peru. Journal of Ethnopharmacology 111:284-294.

Hu J, Deng Y, John RIW, and Thomas FD. 2011. Dicliptera in Flora of China 19: Science Press, Beijing \& Missouri Botanical Garden Press, St. Louis.

Huang S, Deng Y, and Ge X. 2019. The complete chloroplast genome of Aphelandra knappiae (Acanthaceae). Mitochondrial DNA Part B-Resources 4:273-274.

Inkyu P, Sungyu Y, Wook JM, Pureum N, Hyun OL and Byeong CM. 2018. The Complete Chloroplast Genomes of Six Ipomoea Species and Indel Marker Development for the Discrimination of Authentic Pharbitidis Semen (Seeds of I. nil or I. purpurea). Frontiers in plant science 9:965.

IS Choi, R Jansen and T Ruhlman. 2019. Lost and Found: Return of the Inverted Repeat in the Legume Clade Defined by Its Absence. Genome Biology Evolution 11: 1321-1333.

Jerzy Jurka and Charit Pethiyagoda. 1995. Simple Repetitive DNA sequences from Primates: Compilation and Analysis. Journal of Molecular Evolution 40: 120-126.

Peer) reviewing PDF | (2019:06:38740:2:0:NEW 16 Dec 2019) 
458

459

460

461

462

463

464

465

466

467

468

469

470

471

472

473

474

475

476

477

478

479

480

481

482

483

484

485

486

487

488

489

490

491

Jin JJ, Yu WB, Yang JB, Song Y, Yi TS, and Li DZ. 2018. GetOrganelle: a simple and fast pipeline for de novo assembly of a complete circular chloroplast genome using genome skimming data. bioRxiv:256479.

Katoh K, and Standley DM. 2013. MAFFT multiple sequence alignment software version 7: improvements in performance and usability. Molecular biology and evolution 30:772780.

Kearse M, Moir R, Wilson A, Stones-Havas S, Cheung M, Sturrock S, Buxton S, Cooper A, Markowitz S, and Duran C. 2012. Geneious Basic: an integrated and extendable desktop software platform for the organization and analysis of sequence data. Bioinformatics 28:1647-1649.

Khakhlova O, and Bock R. 2006. Elimination of deleterious mutations in plastid genomes by gene conversion. The Plant Journal 46:85-94.

Kiel CA, Daniel TF, Darbyshire I, and McDade LA. 2017. Unraveling relationships in the morphologically diverse and taxonomically challenging. Taxon 66:645-674.Kim K-J, and Lee H-L. 2004. Complete chloroplast genome sequences from Korean ginseng (Panax schinseng Nees) and comparative analysis of sequence evolution among 17 vascular plants. DNA research 11:247-261.

Kurt M. Neubig, W. Mark Whiten, Barbara S. Carlsward, Mario A. Blanco, Lorena Endara, Norris H. Williams, and Michael Moore. 2008. Phylogenetic utility of ycf1 in orchids: a plastid gene more variable than matK. Faculty Research \& Creative Activity 257.

Kurtz S, Choudhuri JV, Ohlebusch E, Schleiermacher C, Stoye J, and Giegerich R. 2001. REPuter: the manifold applications of repeat analysis on a genomic scale. Nucleic acids research 29:4633-4642.

Langmead B, and Salzberg SL. 2012. Fast gapped-read alignment with Bowtie 2. Nature methods 9:357.

León B. 2006. Acanthaceae endémicas del Perú (en línea). Revista peruana de Biología 13(2):23-29.

Li D, Zhao Ch and Liu X. 2018. Coplete chloroplast genome sequences of Kaempferia galanga and Kaempferia elegans: molecular structures and comparative analysis. Molecules 24:474.

Li L, Stoeckert CJ, and Roos DS. 2003. OrthoMCL: identification of ortholog groups for eukaryotic genomes. Genome research 13:2178-2189.

Librado P, and Rozas J. 2009. DnaSP v5: a software for comprehensive analysis of DNA polymorphism data. Bioinformatics 25:1451-1452. 
492 Wang L, Wuyun T, Du H, Wang D and Cao D. 2016. Complete chloroplast genome sequences

493

494

495

496

497

498

499

500

501

502

503

504

505

506

507

508

509

510

511

512

513

514

515

516

517

518

519

520

521

522

523

524 of Eucommia ulmoides: genome structure and evolution. Tree Genetics \& Genomes 12:12.

Lucinda Mcdade, Thomas Daniel and Carrie Kiel. 2008. Toward a comprehensive understanding of phylogenetic relationships among lineages of Acanthaceae S.L. (Lamiales). American Journal of Botany 95:1136-1152.

Mabberley D. 2017. Mabberley's plant-book. A portable dictionary of plants, their classifications and uses, forth edition. Cambridge University Press.

Mader M, Pakull B, Blanc-Jolivet C, Paulini-Drewes M, Bouda Z, Degen B, Small I, and Kersten B. 2018. Complete chloroplast genome sequences of four Meliaceae species and comparative analyses. International journal of molecular sciences 19:701.

Makalowski W and Boguski M. S. 1998. Evolutionary parameters of the transcribed mammalian genome: An analysis of 2,820 orthologous rodent and human sequences. Proceedings of the National Academy of Sciences of the United States of America 95:9407-9412.

Marcondes Oliveira, Alexandre Grillo and Marcelo Tabarelli. 2004. Caracterização da flora dos remanescentes da Usina Serra Grande, Alagoas. Relatório Técnico. Centro de Pesquisas Ambientais do Nordeste, Recife, PE.Meng X-X, Xian Y-F, Xiang L, Zhang D, Shi Y-H, Wu M-L, Dong G-Q, Ip S-P, Lin Z-X, and Wu L. 2018. Complete Chloroplast Genomes from Sanguisorba: Identity and Variation Among Four Species. Molecules 23:2137.

Jiang M, Chen H, He S, Wang L, Chen A and Liu C. 2018. Sequencing, Characterization, and Comparative Analyses of the Plastome of Caragana rosea var. rosea. International Journal of Molecular Sciences 19:1419.

Nylander J. A. A. 2004. MrModeltest v2. Program distributed by the author. Evolutionary Biology Centre, Uppsala University, 2.

Olmstead RG, and Palmer JD. 1994. Chloroplast DNA systematics: a review of methods and data analysis. American journal of botany 81:1205-1224.

Gao QB, Li Y, Gengji ZM, RJ Gornall, Wang JL, Hai-Rui Liu HR, Jia LK and Chen SL. 2017. Population Genetic Differentiation and Taxonomy of Three Closely Related Species of Saxifraga (Saxifragaceae) from Southern Tibet and the Hengduan Mountains. Frontiers in plant science 8:1325.

Ma Q, Li S, Changwei Bi C, Hao Z, Sun C and Ye N. 2017. Complete chloroplast genome sequence of a major economic species, Ziziphus jujuba (Rhamnaceae). Current Genetics 63:117-129. 
525

526

527

528

529

530

531

532

533

534

535

536

537

538

539

540

541

542

543

544

545

546

547

548

549

550

551

552

553

554

555

556

557

558

559
Lu Q, Ye W, Lu R, Xu W and Qiu Y. 2018. Phylogenomic and Comparative Analyses of Complete Plastomes of Croomia and Stemona (Stemonaceae). International journal of molecular sciences 19: 2383.

Qu XJ, Moore MJ, Li DZ, and Yi TS. 2019. PGA: a software package for rapid, accurate, and fexible batch annotation of plastomes. Plant Methods 15:1-12.

Raubeson LA, Peery R, Chumley TW, Dziubek C, Fourcade HM, Boore JL, and Jansen RK. 2007. Comparative chloroplast genomics: analyses including new sequences from the angiosperms Nuphar advena and Ranunculus macranthus. BMC genomics 8:174.

Ronquist F, and Huelsenbeck JP. 2003. MrBayes 3: Bayesian phylogenetic inference under mixed models. Bioinformatics 19:1572-1574.

Sara El-Gebali, Jaina Mistry, Alex Bateman, Sean R. Eddy, Aurelien Luciani, Simon C. Potter, Matloob Qureshi, Lorna J. Richardson, Gustavo A. Salazar, Alfredo Smart, Erik L.L. Sonnhammer, Layla Hirsh, Lisanna Paladin, Damiano Piovesan, Silvio C.E. Tosatto and Robert D. Finn. 2018. The Pfam protein families database in 2019. Nucleic Acid Research gky995.

Särkinen T, and George M. 2013. Predicting plastid marker variation: can complete plastid genomes from closely related species help? PLoS One 8:e82266.

Schattner P, Brooks AN, and Lowe TM. 2005. The tRNAscan-SE, snoscan and snoGPS web servers for the detection of tRNAs and snoRNAs. Nucleic acids research 33:W686W689.

Scotland R, and Vollesen K. 2000. Classification of Acanthaceae. Kew Bulletin :513-589.

Sharp PM, and Li W-H. 1987. The codon adaptation index-a measure of directional synonymous codon usage bias, and its potential applications. Nucleic acids research 15:1281-1295.

Shingo Kikuchi, Jocelyn Bédard, Minako Hirano, Yoshino Hirabayashi, Maya Oishi, Midori Imai, Mai Takase, Toru Ide and Masato Nakai. Uncoverign the protein translocon at the chloroplast inner envelope membrane. 2013. Science 339:571.

Stamatakis A. 2014. RAxML version 8: a tool for phylogenetic analysis and post-analysis of large phylogenies. Bioinformatics 30:1312-1313.

Steane DA. 2005. Complete nucleotide sequence of the chloroplast genome from the Tasmanian blue gum, Eucalyptus globulus (Myrtaceae). DNA research 12:215-220.

Swofford DL. 2003. PAUP. Phylogentic Analysis Using Parsimony (* and Other Methods). Version 4. Sunderland: Sinauer Associates Press.

Telefo P, Moundipa P, and Tchouanguep F. 2002. Oestrogenicity and effect on hepatic metabolism of the aqueous extract of the leaf mixture of Aloe buettneri, Dicliptera verticillata, Hibiscus macranthus and Justicia insularis. Fitoterapia 73:472-478.

Peer] reviewing PDF | (2019:06:38740:2:0:NEW 16 Dec 2019) 
560 Thiel T, Michalek W, Varshney R, and Graner A. 2003. Exploiting EST databases for the 561 development and characterization of gene-derived SSR-markers in barley (Hordeum 562 vulgare L.). Theoretical and applied genetics 106:411-422.

563 Victor Aredo, Jhan Carranza-Cabrera and Raúl Siche. 2017. Inventory of plant species of La $564 \quad$ Libertad (Peru) and analysis of its agro-industrial potential. Agroindustrial Science 7:87$565 \quad 104$.

566 Wang RJ, Cheng C-L, Chang CC, Wu CL, Su TM, and Chaw S-M. 2008. Dynamics and 567 evolution of the inverted repeat-large single copy junctions in the chloroplast genomes of monocots. BMC evolutionary biology 8:36.

Weng ML, Blazier JC, Govindu M, and Jansen RK. 2013. Reconstruction of the ancestral plastid genome in Geraniaceae reveals a correlation between genome rearrangements, repeats, and nucleotide substitution rates. Molecular biology and evolution 31:645-659.

Wick RR, Schultz MB, Zobel J, and Holt KE. 2015. Bandage: interactive visualization of de novo genome assemblies. Bioinformatics 31:3350-3352.

Wicke S, Schneeweiss GM, Müller KF, and Quandt D. 2011. The evolution of the plastid chromosome in land plants: gene content, gene order, gene function. Plant molecular biology 76:273-297.

Wojciech Makalowski and Mark S. Boguski. 1998. Evolutionary parameters of the transcribed mammalian genome: An analysis of 2,820 orthologous rodent and human sequences. Proceedings of the National Academy of Sciences of the United States of America 95: 9407-9412.

Wu Y, Liu F, Yang DG, Li W, Zhou XJ, Pei XY, Liu YG, He KL, Zhang WS, and Ren ZY. 2018. Comparative chloroplast genomics of Gossypium species: Insights into repeat sequence variations and phylogeny. Frontiers in plant science 9:376.

Feng X, Yuan X, Sun Y, Hu Y, Saman Zulfiqar, Ouyang X, Dang M, Zhou H, Keith Woeste and Zhao P. 2018. Resources for studies of iron walnut (Juglans sigillata) gene expression, genetic diversity, and evolution. Tree Genetics \& Genomes 14:51.

Yang JB, Li DZ, and Li HT. 2014a. Highly effective sequencing whole chloroplast genomes of angiosperms by nine novel universal primer pairs. Molecular Ecology Resources 14:1024-1031.

Yang Y, Yuanye D, Qing L, Jinjian L, Xiwen L, and Yitao W. 2014b. Complete chloroplast genome sequence of poisonous and medicinal plant datura stramonium: organizations and implications for genetic engineering. PLoS One 9:e110656. 
593 Yang Z and Willie J. Swanson. 2002. Codon-Substitution Models to Detect Adaptive Evolution 594 that Account for Heterogeneous Selective Pressures Among Site Classes. Molecular $595 \quad$ Biology and Evolution 19:49-57.

596 Yang Z. 2007. PAML 4: phylogenetic analysis by maximum likelihood. Molecular biology and 597 evolution 24:1586-1591.

598 Yang Z, and Nielsen R. 2000. Estimating synonymous and nonsynonymous substitution rates $599 \quad$ under realistic evolutionary models. Molecular biology and evolution 17:32-43.

600 Yi DK, and Kim KJ. 2012. Complete chloroplast genome sequences of important oilseed crop $601 \quad$ Sesamum indicum L. PLoS One 7:e35872.

602 Zhao Z, Wang X, Yu Y, Yuan S, Jiang D, Zhang Y, Zhang T, Zhong W, Yuan Q and Huang L. 603 2018. Complete chloroplast genome sequences of Dioscorea: Characterization, genomic 604 resources, and phylogenetic analyses. Peerj 6:e6032.

605 Zhang K, Zhu H, and Gao Y. 2010. Research on active extracts of Dicliptera chinensis on liver 606 protection. China journal of Chinese materia medica 35:497-498.

607

608 
Figure 1

Gene maps of chloroplast genomes.

(A) Dicliptera acuminata; (B) D. peruviana; (C) D. montana; (D) D. ruiziana; (E) D. mucronata. Genes shown outside of the circle are transcribed clockwise, whereas genes inside of the circle are transcribed counterclockwise. The colored bars indicate known protein-coding genes, tRNA and rRNA. The dark gray area in the inner circle indicates GC content, while the light gray area indicates AT content. LSC, large single copy; SSC, small single copy; IR, inverted repeats. 

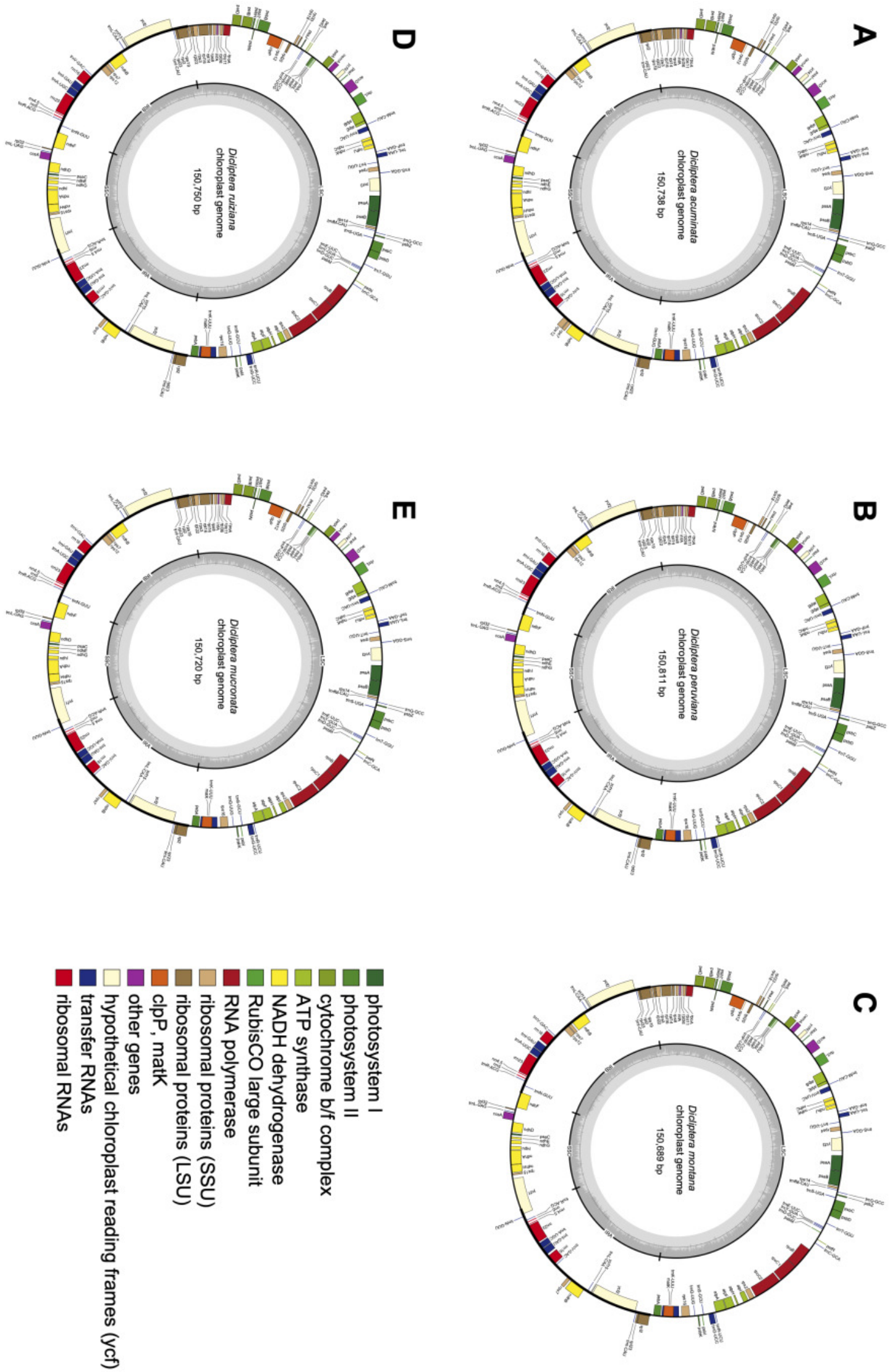
Figure 2

Comparison of the border regions of the LSC, SSC and IR among six Acanthaceae chloroplast genomes.

The IRb/SSC junction extended into the $y c f 1$ genes creating various lengths of $y c f 1$ pseudogenes ( $\Psi y c f 1)$ among the six cp genomes. The number above, below or adjacent to genes shows the distance between the ends of genes and the boundary sites. The figure features are not to scale.

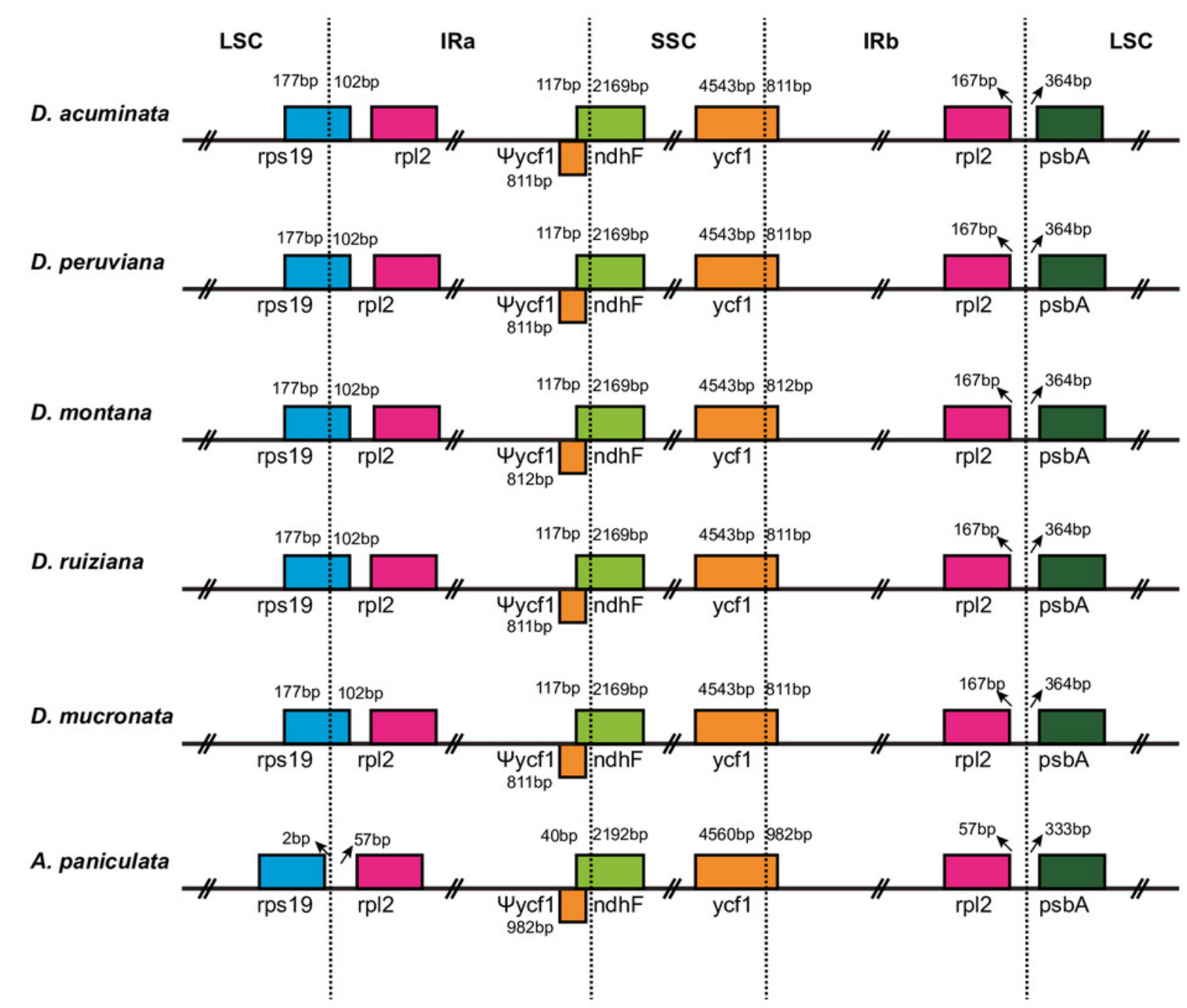


Figure 3

\section{Comparison of the five Dicliptera chloroplast genomes using mVISTA.}

CNS indicates conserved noncoding sequences. The Y-scale represents the percent identity between $50 \%$ and $100 \%$.

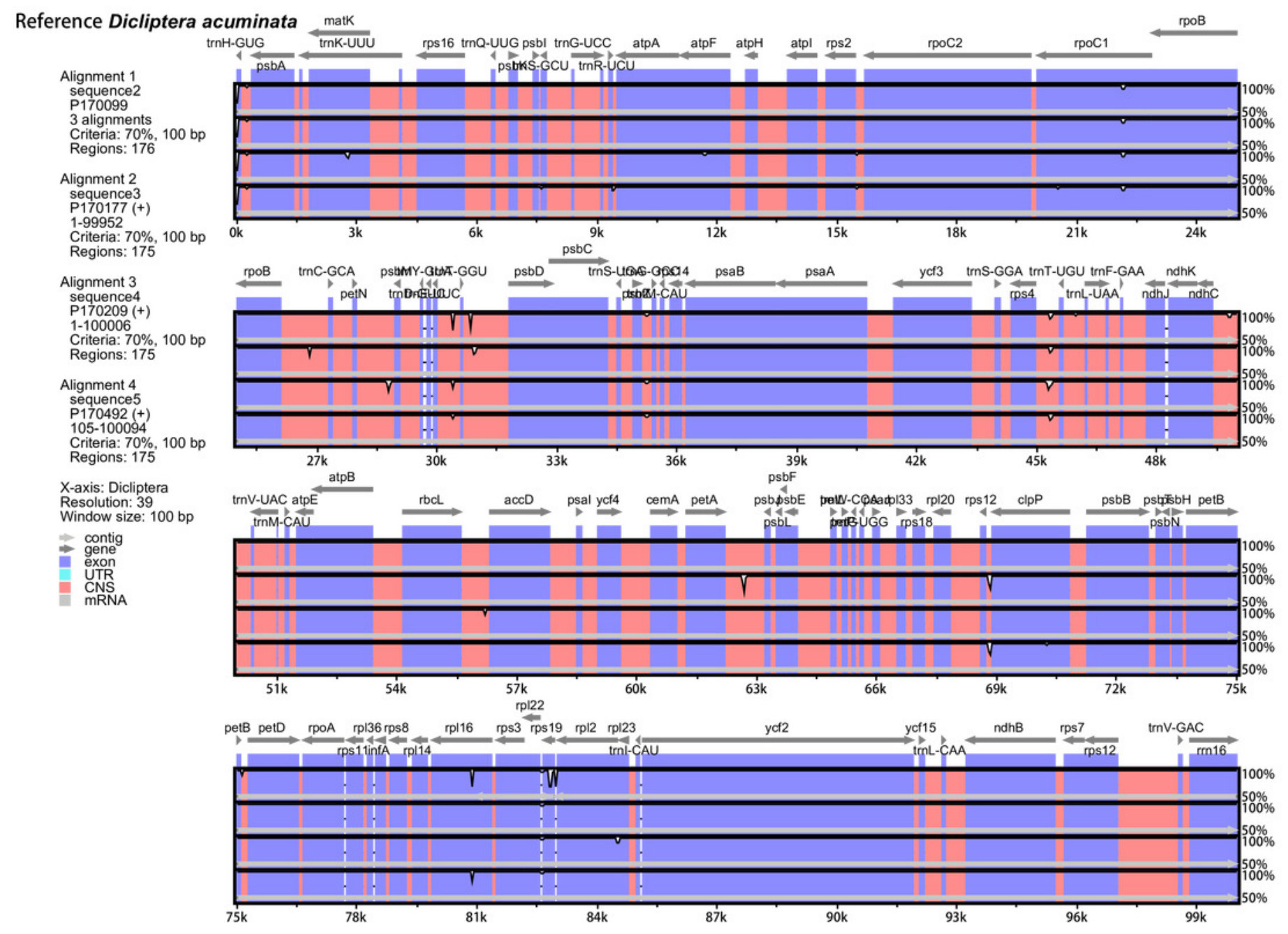


Figure 4

Comparative analysis of the nucleotide diversity (Pi) value among five Dicliptera chloroplast genomes.
(A) Coding regions. (B) Non-coding regions. 

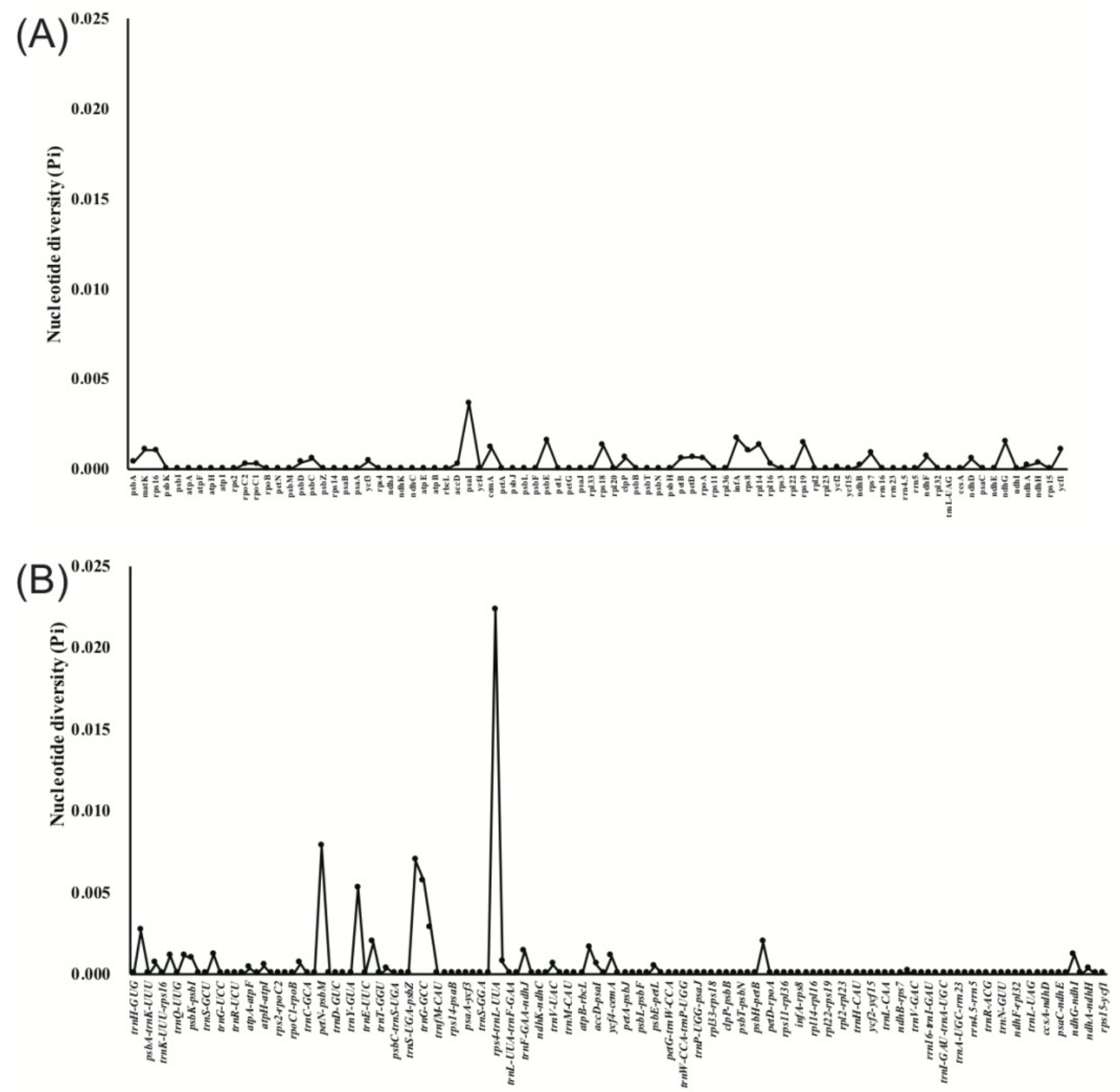
Figure 5

Amino acid frequencies in five Dicliptera species protein-coding sequences.

As shown in the column diagram, Leucine was the most frequent amino acid (10.8\%), Cysteine was the least (1.2\%). 


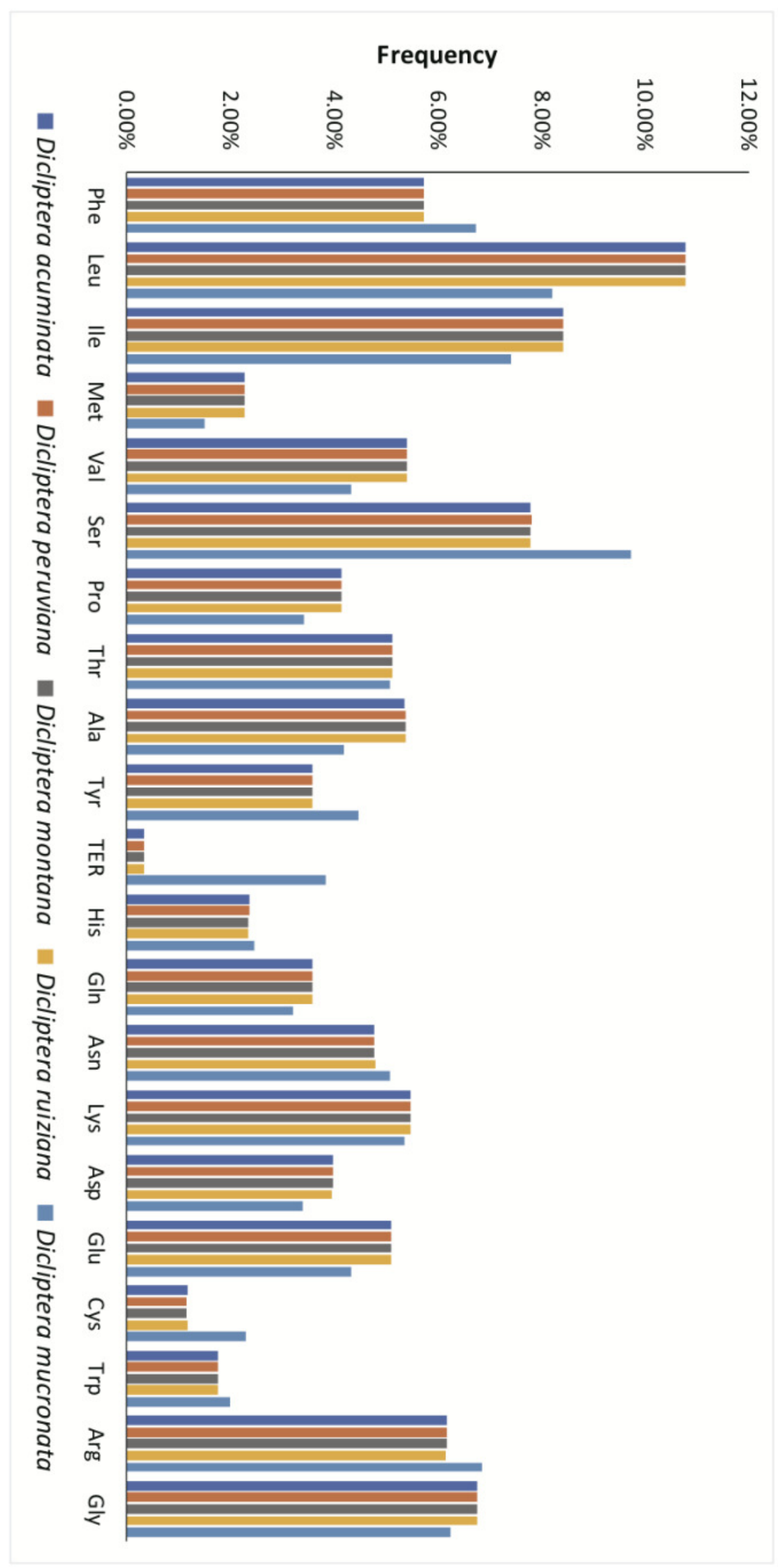


Figure 6

The type and presence of simple sequence repeats (SSRs) and long repeated sequences in the chloroplast genomes of five Dicliptera species.

(A) Percentage of SSR types; (B) Number of SSRs and their types; (C) Percentage of five repeat types; (D) Number of five repeats types. 


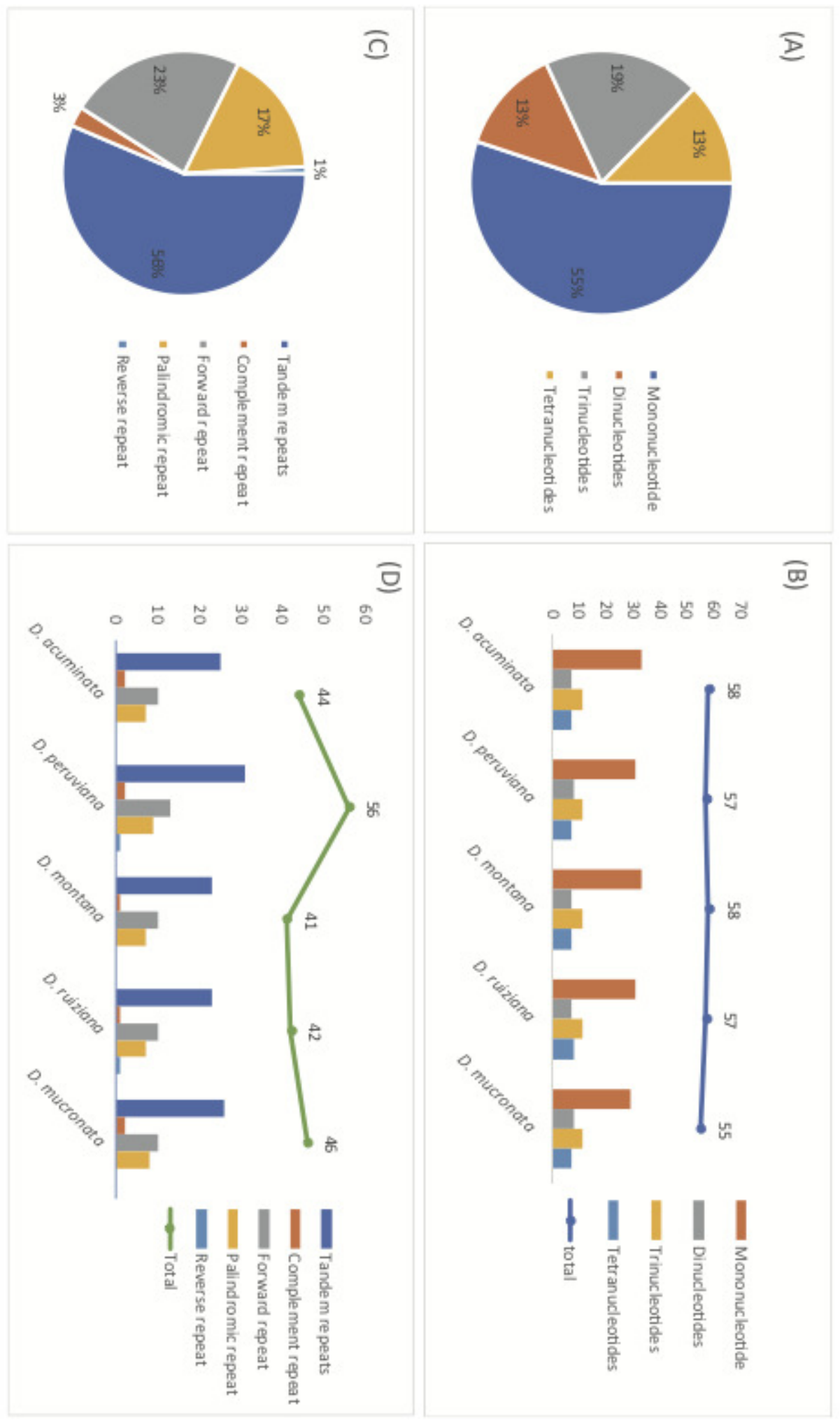




\section{Figure 7}

the Maximum Likelihood (ML) tree of Acanthaceae.

Numbers associated with branches are ML bootstrap values, MP bootstrap values and Bayesian posterior probabilities, respecively. Hyphens indicate the bootstrap support or posterior probability lower than $50 \%$ or 0.5 . Mentha spicata (NC_037247) and Sesamum indicum (NC_016433) were used as outgroups. 


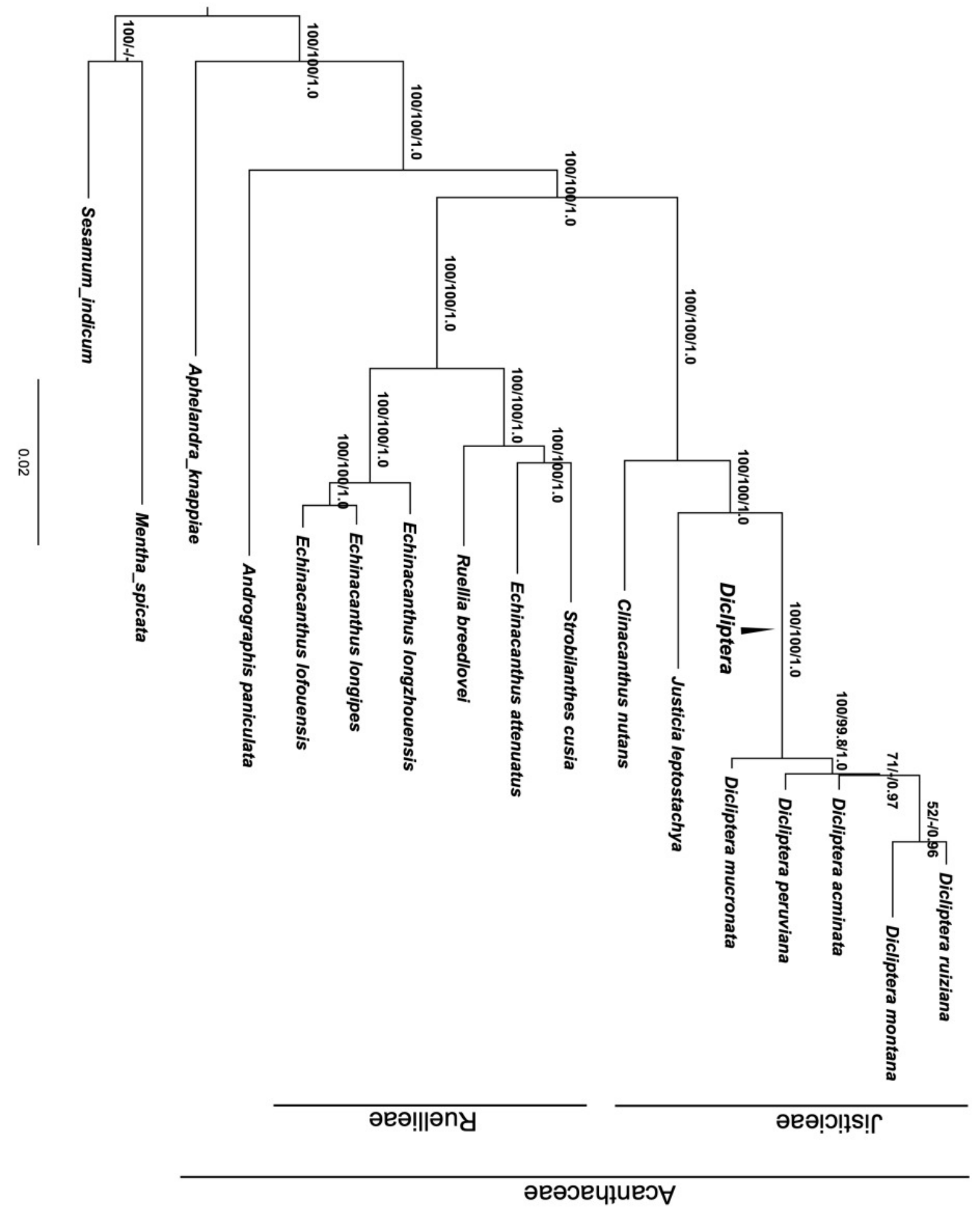


Figure 8

Synonymous (KS) substitution rates and $\omega$ values ( $\omega=K A / K S$ ) among all Acanthaceae species.

as shown in the column diagram, the order of genes is alphabetical, $\omega$ value of ycf15 gene (1.4453) is clearly higher than other genes. 


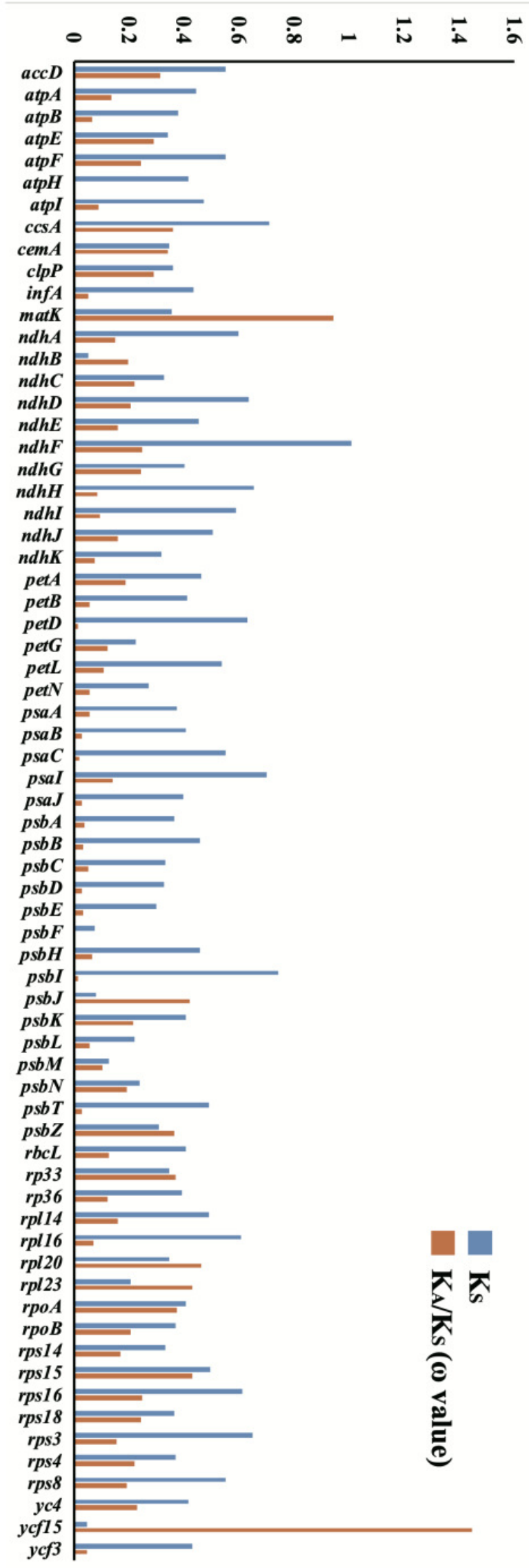




\section{Table $\mathbf{1}$ (on next page)}

Morphological differences among Dicliptera acuminata, D. peruviana, D. montana, $D$. mucronata and $D$. ruiziana. 


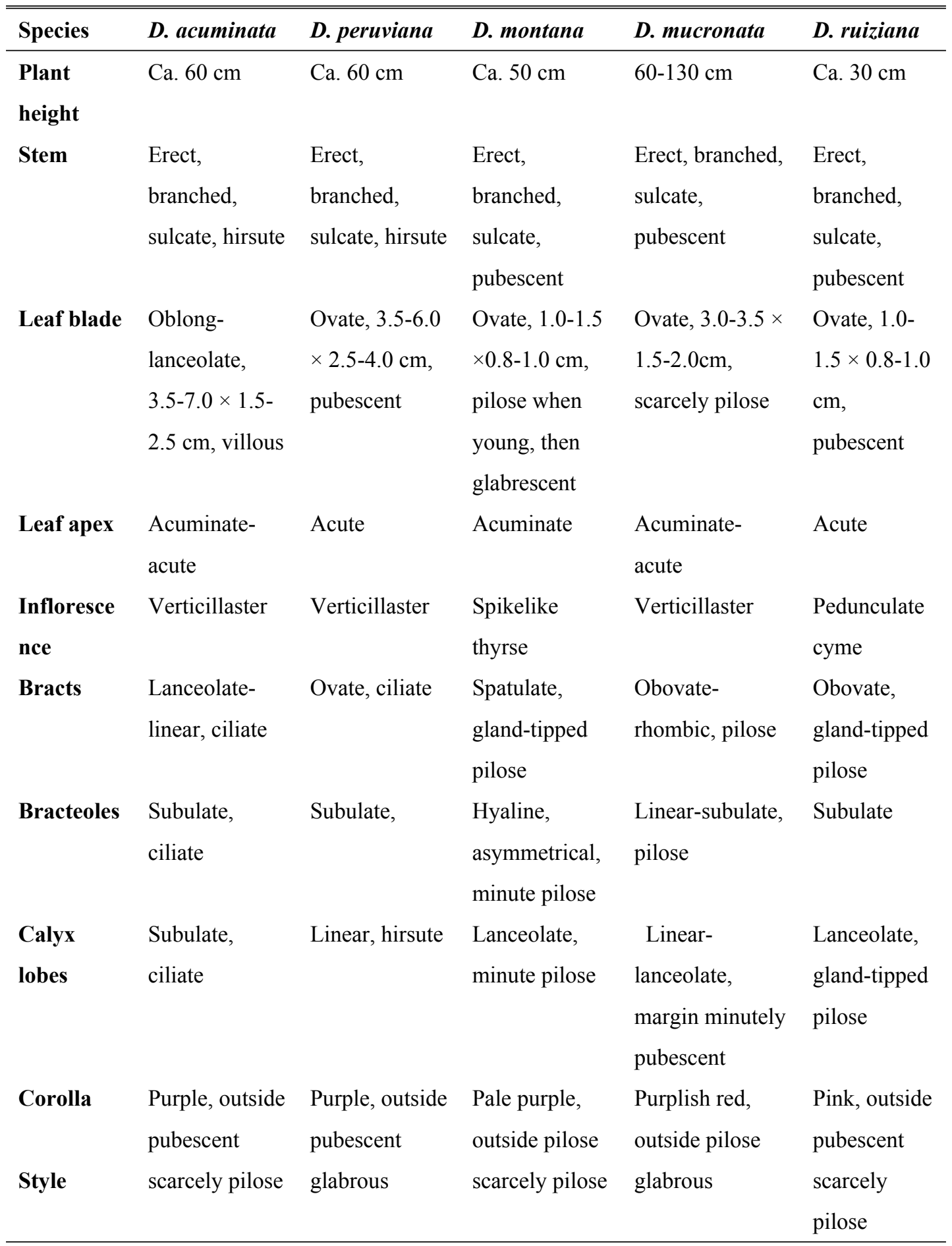


Table 2 (on next page)

Species information and Genome features of the chloroplast genomes of five Dicliptera species. 


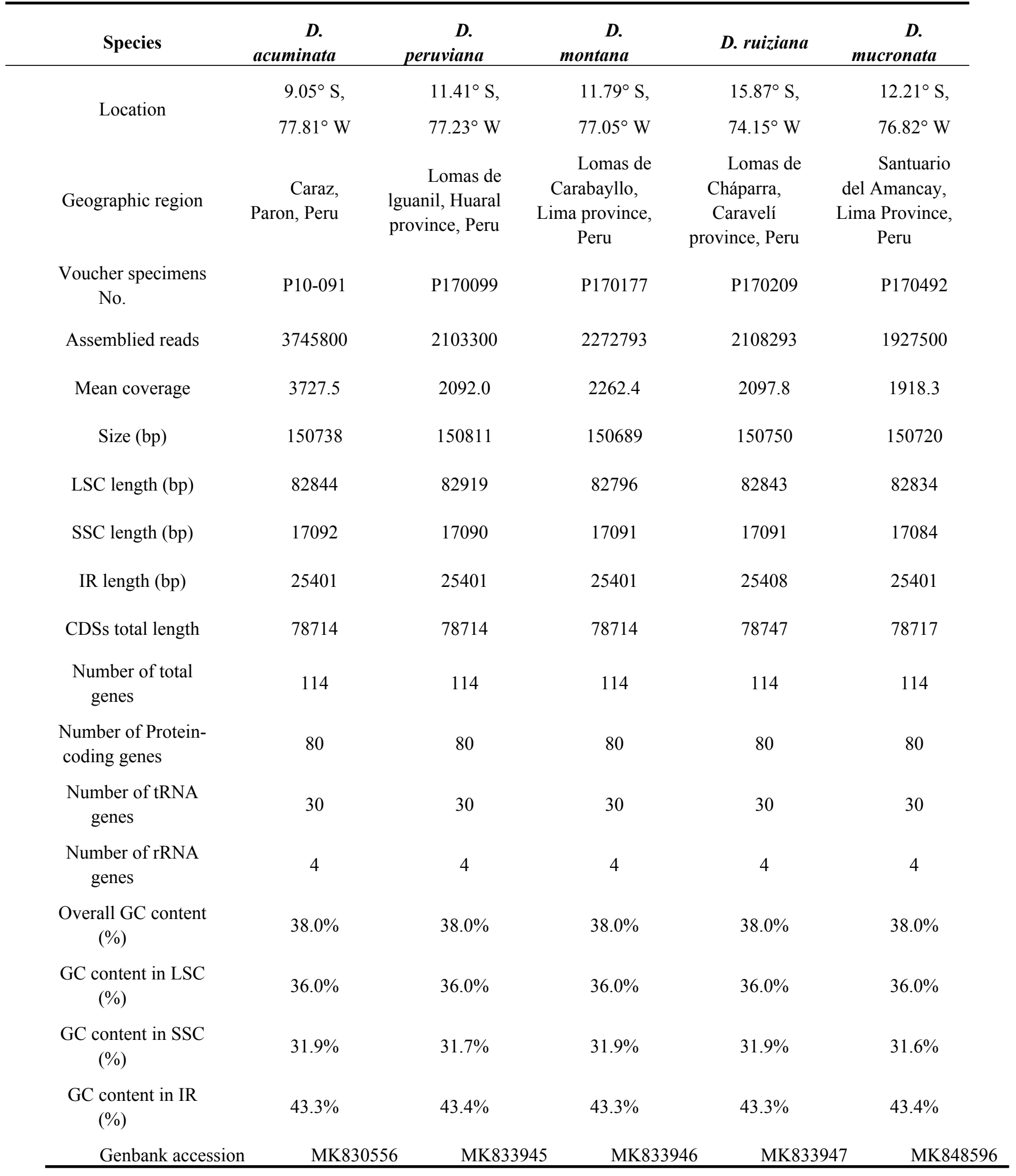


number

2 


\section{Table 3 (on next page)}

The polymorphic SSRs among five Dicliptera species.

LSC, large single copy; SSC, small single copy. 


\begin{tabular}{|c|c|c|c|}
\hline Type & $\begin{array}{c}\text { D. acuminata/D. } \\
\text { peruviana/D. montana/D. } \\
\text { ruiziana/D. mucronata }\end{array}$ & Location & Regions \\
\hline $\mathbf{A}$ & $11 / 11 / 10 / 11 / 13$ & psbI-trnS-GCU & LSC \\
\hline $\mathbf{T}$ & $0 / 0 / 0 / 10 / 0$ & $\operatorname{trnS}-G C U-\operatorname{trn} G-U C C$ & LSC \\
\hline $\mathbf{T}$ & $13 / 13 / 14 / 13 / 13$ & $\operatorname{trnR}-U C U-a t p A$ & LSC \\
\hline $\mathbf{A}$ & $12 / 11 / 11 / 10 / 11$ & $a p t F$ & LSC \\
\hline $\mathbf{A}$ & $10 / 10 / 10 / 0 / 0$ & atpI-rps 2 & LSC \\
\hline TA & $0 / 0 / 0 / 0 / 8$ & $\operatorname{trn} E-U U C-\operatorname{trn} T-G G U$ & LSC \\
\hline AT & $0 / 9 / 0 / 0 / 0$ & $\operatorname{trn} E-U U C-\operatorname{trn} T-G G U$ & LSC \\
\hline $\mathbf{T}$ & $13 / 10 / 12 / 16 / 14$ & $p s b Z-t r n G-G C C$ & LSC \\
\hline G & $11 / 11 / 12 / 9 / 8$ & $p s b Z-t r n G-G C C$ & LSC \\
\hline $\mathbf{T}$ & $10 / 10 / 10 / 10 / 11$ & rps4-trnT-UGU & LSC \\
\hline ATAA & $3 / 3 / 3 / 6 / 3$ & rps4-trnT-UGU & LSC \\
\hline TA & $6 / 7 / 7 / 7 / 7$ & rps4-trnT-UGU & LSC \\
\hline $\mathbf{T}$ & $12 / 11 / 13 / 13 / 11$ & $n d h C-t r n V-U A C$ & LSC \\
\hline $\mathbf{T}$ & $12 / 11 / 11 / 12 / 11$ & $p s a I-y c f 4$ & LSC \\
\hline $\mathbf{T}$ & $11 / 10 / 11 / 11 / 10$ & pet $G$-trnW-CCA & LSC \\
\hline $\mathbf{T}$ & $11 / 10 / 10 / 10 / 0$ & clpP intron & LSC \\
\hline TA & $7 / 6 / 6 / 6 / 6$ & rpl22-rps19 & LSC \\
\hline $\mathbf{T}$ & $10 / 10 / 10 / 10 / 11$ & $n d h F-r p l 32$ & $\mathrm{SSC}$ \\
\hline $\mathbf{A}$ & $10 / 11 / 10 / 10 / 10$ & $n d h D-p s a C$ & $\mathrm{SSC}$ \\
\hline $\mathbf{G}$ & $11 / 0 / 11 / 11 / 10$ & $n d h G-n d h I$ & $\mathrm{SSC}$ \\
\hline $\mathbf{A}$ & $11 / 10 / 10 / 10 / 0$ & $n d h A$ intron & $\mathrm{SSC}$ \\
\hline
\end{tabular}

